\title{
MIGRAÇÃO E CRISE: O RETORNO DOS IMIGRANTES BRASILEIROS EM PORTUGAL
}

\author{
Duval Fernandes* \\ Maria da Consolação G. de Castro**
}

\begin{abstract}
Frente à crise iniciada em 2008, a migração de retorno passou a compor, em todo o mundo, a cena dos trajetos migratórios do segundo decênio do Século XXI. No caso brasileiro, este movimento toma especial importância, pois a situação econômica do país, naquele momento, mais favorável em relação aos países centrais do sistema capitalista, funcionou como um fator de atração e contribuiu para a aceleração de alguns planos de retorno já latentes. Este texto, utilizando dados levantados juntos a imigrantes de retorno, entrevistados nos estados de Minas Gerais e Rondônia, apresenta um quadro da situação vivida no exterior e a situação encontrada no Brasil quando da nova migração.
\end{abstract}

Palavras-chave: migração internacional, retorno, projeto migratório.

\section{Introdução}

Em 2003, durante a visita do Presidente Lula a Portugal foi assinado o "Acordo Brasil-Portugal sobre Contratação Recíproca de Nacionais", entre os Governos do Brasil e Portugal. Este acordo, que ficou conhecido por Acordo Lula, pôs fim a uma longa disputa sobre a sorte de imigrantes brasileiros que viviam em Portugal, estabelecendo várias facilidades para que os brasileiros residentes naquele país pudessem regularizar a sua situação migratória, sobretudo os odontólogos que exerciam sua profissão em Portugal.

Além de ser um marco para a regularização da situação de vários brasileiros, este acordo é também o reconhecimento oficial de uma situação, até então, pouco acompanhada pelo governo brasileiro, a emigração, que

\footnotetext{
* Professor do Programa de Pós-Graduação em Geografia da PUC Minas e Coordenador do Grupo de Estudos Distribuição Espacial da População - GEDEP. Belo Horizonte - MG/Brasil.

** Professora do Curso de Serviço Social da PUC Minas e Pesquisadora do GEDEP. Belo Horizonte MG/Brasil.
} 
naquele momento, levava um número crescente de brasileiros a buscar oportunidades no exterior.

Por diversas razões, dentre elas o idioma e a facilidade de entrada em solo português, os brasileiros optaram por emigrar para Portugal, o que transformou a comunidade de brasileiros naquele país no maior contingente de estrangeiros em terras lusitanas.

$\mathrm{O}$ volume deste contingente nunca foi realmente conhecido. Estimativas das autoridades consulares brasileiras indicavam que o montante de brasileiros que viviam em Portugal, antes da crise de 2008 ficava próximo à casa dos $200.000^{1}$ imigrantes. Mais modestos, os números do Serviço de Estrangeiros e Fronteiras - SEF² apontavam que, aproximadamente, 120.000 brasileiros tinham título de residência em Portugal no ano de 2011. Este número representava mais de $25,0 \%$ do total de estrangeiros residentes no país, fazendo dos brasileiros o contingente mais importante de imigrantes em Portugal.

No momento em que a crise de 2008 atinge Portugal, o mercado de trabalho para os imigrantes passa por momentos difíceis, com uma taxa de desemprego para esta subpopulação mais elevada do que para os nacionais. Assim, segundo dados do Instituto Nacional de Estatística de Portugal INE, em 2011, enquanto o desemprego dos portugueses atingia, aproximadamente, $13 \%$ da população nativa economicamente ativa, no caso dos imigrantes a taxa chegava a mais de $20 \%$.

Além das dificuldades de se encontrar trabalho, vários brasileiros se viram privados do apoio dos serviços sociais portugueses que, por cortes orçamentários, reduziram em muito o atendimento às populações em situação de vulnerabilidade. Do outro lado do Atlântico, o Brasil na mesma época, conhecia as maiores taxas de crescimento econômico observada nas últimas décadas. Esta situação ampliou a oferta de postos de trabalho o que reduziu a taxa de desemprego no país a níveis nunca antes vistos, sendo que, para alguns analistas, o país vivia em situação de pleno emprego.

Se de um lado a situação de Portugal e dos países europeus em geral, contribuíam para a criação de situações propícias para a partida, na América do Sul, e o Brasil em particular, ofereciam atrativos para a absorção da mão de obra excedente em Portugal, principalmente entre os brasileiros.

Assim, ainda não completada a primeira década do novo milênio, o país assistia, uma vez mais, à alteração da sua dinâmica migratória internacional.

\footnotetext{
1 Cf. <http://www.brasileirosnomundo.itamaraty.gov.br/a-comunidade/estimativas-populacionaisdas-comunidades/Brasileiros\%20no\%20Mundo\%20-\%20Estimativas.pdf >

${ }^{2}$ Anuário Estatístico do SEF 2012 (<http://sefstat.sef.pt/Docs/Rifa\%202012.pdf>).
} 
Se os anos de 1980 foram marcados por crescentes saldos negativos no fluxo migratório internacional com a saída de milhares de brasileiros ${ }^{3}$, os resultados do Censo Demográfico de 2010, mostraram que a imigração que tinha o Brasil como destino, passava a ter importante papel e a participação dos brasileiros retornados responderia por mais de 65,0\% deste fluxo.

É no contexto da ampliação deste movimento de retorno dos brasileiros ao país, que este artigo propõe analisar o retorno daqueles imigrantes que optaram por viver em Portugal. O texto tem por base duas pesquisas realizadas em datas recentes que tratam da migração de retorno de brasileiros da Europa, mais especificamente de Portugal. A primeira, financiada pelo $\mathrm{CNPq}^{4}$, foi realizada em 2011 e 2012, a segunda ${ }^{5}$, realizada no âmbito do Projeto ITINERIS ${ }^{6}$ que contou com apoio do ICMPD $^{7}$ e do Ministério do Trabalho e Emprego.

Além desta introdução é apresentado um breve resumo, como referencial teórico, seguido do quadro dos resultados das pesquisas e conclusões.

\section{Alguns aspectos teóricos sobre as migrações internacionais}

Sob o ponto de vista teórico, mesmo neste início do século XXI, ainda não foi possível estabelecer uma teoria geral para a migração, incluindo a migração de retorno. Segundo Zlotnik ${ }^{8}$, considerando as múltiplas facetas da migração, várias disciplinas, ou áreas do conhecimento, vêm aportando contribuições que buscam explicar a natureza, o desenvolvimento e a gênese de casos singulares de migração. Apesar de ainda não ser possível contar, no campo teórico, com uma visão geral e única, há a possibilidade de se definir algumas linhas de contribuições que buscam explicar a migração, quer seja ela interna a um país ou internacional.

Segundo Arango 9 a teoria da migração internacional, entendida como tal, só começa a tomar corpo na segunda metade do século XX. Antes desta

\footnotetext{
${ }^{3}$ Estimativas do Ministério das Relações Exteriores indicavam que em 2011, mais de 3,1 milhões de brasileiros viviam no exterior (Cf. <http:/www.brasileirosnomundo.itamaraty.gov.br/acomunidade/estimativas-populacionais-das-comunidades/Brasileiros\%20no\%20Mundo\%20 2011\%20-\%20Estimativas\%20-\%20Terceira\%20Edicao\%20-\%20v2.pdf>).

${ }^{4}$ Projeto CNPq no 477167/2010-1: "A crise e a migração de retorno: o caso dos imigrantes brasileiros em Portugal".

5 "Migração Brasil - Europa: a situação dos migrantes brasileiros retornados da Europa no início do Século XX".

${ }^{6}$ Projeto "Itineris: Proteção dos direitos dos migrantes contra a exploração, do Brasil para EstadosMembros da União Europeia".

${ }^{7}$ ICMPD - International Centre for Migration Policy Development.

${ }^{8}$ ZLOTNIK, Hania. Théories sur les migrations internationales.

${ }^{9}$ ARANGO, Joaquín. La explicación teórica de las migraciones: luz y sombra.
} 
época, vários foram os esforços para a construção de uma teoria, sendo o mais conhecido deles a obra de Ravestein ${ }^{10}$. No entanto, as contribuições da economia ao campo da migração remontam ainda à época de Adam Smith, quando se via, como causa da migração de trabalhadores, as diferenças entre a demanda e a oferta de trabalho nas regiões em estudo.

Esta visão indica que, no âmbito da economia, a migração internacional é, na realidade, um mecanismo para a redistribuição dos trabalhadores, ou seja, da população em idade ativa. As visões modernas desta teoria, também conhecidas como macroteoria neoclássica e microteoria neoclássica, buscam a explicação para a migração internacional na relação entre trabalho e capital.

No plano macro, este aporte trata da redistribuição de fatores de produção em respostas às modificações dos seus preços relativos. A migração internacional seria o resultado das desigualdades na distribuição espacial do capital e do trabalho. Países com escassa mão de obra tenderiam a oferecer salários mais elevados, enquanto países com abundância de mão de obra teriam tendência a menores salários. Como maiores salários seriam grandes atrativos para a população residente nos países de baixos salários, o movimento natural seria a migração dos residentes destes últimos para os primeiros. Com isto, a oferta de mão de obra se ampliaria nos primeiros países, levando a uma redução dos salários e ao equilíbrio entre as duas regiões. Neste sentido, a migração funcionaria como um fator para a melhor redistribuição geográfica dos recursos, no caso a mão de obra.

No aspecto micro, segundo Castles e Miller ${ }^{11}$, o conceito central da teoria neoclássica é o de "capital humano", que poderia ser descrito como a decisão pessoal em investir na migração, da mesma forma que se decide investir em educação ou outra atividade de aperfeiçoamento, pois isto contribuiria para ampliar a capacitação do migrante e trazer ganhos futuros. A decisão de emigrar considera as possibilidades de ganhos futuros na região de destino e leva em conta os custos, efetivo e não mensuráveis, deste deslocamento. Se o ganho for maior que as "despesas" há espaço para a migração, caso contrário não se migra. Em resumo, a migração seria um ato voluntário, individual e espontâneo, resultante de uma avaliação do custo-benefício de se fazer o deslocamento.

Segundo Soares ${ }^{12}$, não há antagonismo entre macro e microteoria neoclássicas, no entanto é importante lembrar que ambas têm limites, uma vez que não consideram questões ligadas às políticas nacionais e à economia inter-

\footnotetext{
${ }^{10}$ RAVENSTEIN, Ernest George. As leis da migração.

${ }^{11}$ CASTLES, Stephen; MILLER, Mark. The age of migration: international population movements in the modern world.

12 SOARES, Weber. Da metáfora à sustância: redes sociais, redes migratórias e migração nacional e internacional em Valadares e Ipatinga.
} 
nacional. Além disso, as hipóteses de partida não são realistas e os efeitos reais da migração de trabalho diferem, sensivelmente, dos preditos nestas teorias ${ }^{13}$.

Algumas constatações empíricas contribuem para mostrar os limites desta teoria. Por exemplo, há casos em que não são os mais pobres que migram e sim os mais qualificados que têm uma propensão maior a emigrar e, dependendo da situação, contribuem para ampliar as desigualdades entre o país de destino e o de origem. Ademais, muitas vezes os países fornecedores de mão de obra possuem salários bem superiores àqueles dos países mais pobres. Afinal, a migração internacional é um empreendimento custoso e os migrantes, geralmente, partem de regiões que estão experimentando crescente integração com a economia internacional ${ }^{14}$.

O reconhecimento dos limites das teorias neoclássicas levou a novas proposições sobre a relação economia e migração, que ficaram mais conhecidas como nova economia da migração. Este segmento também confere importante papel ao nível micro, mas neste caso as decisões não seriam só individuais, mas também norteadas pelo coletivo, notadamente, no nível da família ou do domicílio. As contribuições desta proposta teórica têm grande importância para a explicação da relação entre desenvolvimento econômico e migração, uma vez que há o entendimento de que o processo migratório ultrapassa a simples relação da diferença salarial, incorporando às análises as imperfeições do mercado e a ação governamental. No entanto, as comprovações empíricas repousam sobre trabalhos direcionados para áreas onde circunstâncias especiais levam à migração, como estudos que têm em conta, povoados mexicanos com longa tradição de migração para os USA ${ }^{15}$. Em resumo, o foco de análise desta teoria é a região de origem, onde as causas e consequências da emigração são analisadas.

Em contraposição à visão da escolha racional, hipótese subjacente tanto nas teorias neoclássicas como na nova economia da migração, a teoria do mercado dual do trabalho ${ }^{16}$ postula que a migração internacional, de trabalhadores de um país em desenvolvimento para um país desenvolvido, resulta de uma demanda permanente de trabalhadores inerente à estrutura econômica do país desenvolvido. Neste país existiriam trabalhos de baixa qualificação e não estáveis, que surgem pela convivência de um setor econômico com intensivo uso de capital e outro com intensivo uso de trabalho e baixa produtividade, o que faz surgir um mercado segmentado. Por conta

\footnotetext{
13 ZLOTNIK, op. cit.

${ }^{14}$ McGOVERN, Patrick. Immigration, labour markets and employment relations.

${ }^{15}$ ARANGO, op. cit.

${ }^{16}$ PIORE, Michael J. Birds of Passage: migrant labor in industrial societies.
} 
das características do trabalho deste último segmento - baixa remuneração, menor importância social - os trabalhadores nativos não estão propensos a desempenhá-lo. Uma ampliação dos salários destes postos de trabalho não iria contribuir para solucionar o problema e sim gerar insatisfações, podendo comprometer a hierarquia salarial. Estes fatores iriam gerar uma demanda por trabalhadores imigrantes e, com isto, os fluxos migratórios.

Apesar de avançar na tentativa de teorização, esta proposta ainda não consegue ter um poder explicativo amplo. Em primeiro lugar, não se pode considerar que a demanda nas sociedades receptoras sejam as únicas forças que levam à migração. Há de considerar o efeito de expulsão existente nas sociedades de origem. Outro aspecto a ser considerado é que, na atualidade, a participação do recrutamento de trabalhadores é reduzida no quadro das migrações internacionais. Pode-se argumentar, como o faz Arango ${ }^{17}$, que, em alguns casos, a oferta de mão de obra dos imigrantes gera a sua própria demanda, como por exemplo, a criação de postos de trabalhos ligados ao atendimento das demandas dos imigrantes residentes.

Ao lado desta visão econômica, merece ser mencionada a abordagem que trata das redes migratórias ou redes sociais ${ }^{18}$. As redes migratórias podem ser definidas como o conjunto de relações interpessoais que vinculam imigrantes, emigrantes retornados ou candidatos à migração com parentes, amigos ou compatriotas, quer seja no país de destino, quer seja no país de origem. Estas redes proporcionam informações, indicações de emprego, moradia e uma série de apoios de natureza diversa. Elas podem ser vistas como um capital social que irá permitir o acesso a empregos com melhor remuneração e outros bens de valor econômico.

Apesar de não poder ser considerada como uma teoria completa, esta abordagem permite explicarvárias situações que surgiram com o desenvolvimento recente do processo migratório. Muitos dos deslocamentos realizados na atualidade têm a sua razão, na existência de redes sociais e fatores como a reunificação familiar, que está na ordem do dia de muitos países de destino. Por se situar entre a visão micro e macro ela contribui para o preenchimento de um vácuo teórico, mas ainda necessita de ampliar seu foco de análise.

Segundo Zlotnik ${ }^{19}$, apesar dos grandes progressos para a compreensão dos mecanismos que conduzem ao nascimento da migração, do desenvolvimento dos fluxos migratórios e da identificação das suas inter-

\footnotetext{
17 Ibidem.

18 SOARES, op. cit.; REZENDE, Dimitri. Reflexões sobre os sistemas de migração internacional: proposta para uma análise estrutural dos mecanismos intermediários.

19 ZLOTNIK, op. cit.
} 
relações, ainda falta uma abordagem holística que possa incorporar não só os principais atores (país de origem, país de destino e migrante), mas também uma série de situações intermediárias e a interação destes atores no próprio processo da migração e na formação do fluxo migratório.

No caso do retorno, as carências teóricas ainda são maiores. Alguns autores indicam que retornar seria como uma nova emigração ${ }^{20}$, só que mais difícil, pois volta-se a um local que acredita-se conhecer, mas de onde se saiu e não acompanhou as mudanças. No imaginário daquele que retorna tudo está parado no tempo, à época da emigração e a frustração pode causar mais problemas do que os encontrados no local de destino quando da partida.

No entanto, como lembra Gmelch ${ }^{21}$ os motivos do retorno podem ser vários. Por exemplo, questões econômicas adversas no país de destino por conta de crises econômicas. Fatores ligados às relações pessoais, saudade dos que ficaram e necessidade de auxiliar parentes que estão com idade avançada, também são fatores que concorrem para o retorno. Não há um perfil único que se possa indicar, mas Gmelch $^{22}$ aponta para uma possível categorização. Há aqueles que voltam após cumprir o projeto migratório uma vez atingido o objetivo fixado no momento da partida. Outros voltam mesmo que o desejo maior fosse de ficar, mas são impelidos, por diversos fatores, a fazer o novo percurso. E, em um último grupo estariam aqueles que, planejavam uma migração permanente, mas optaram por retornar.

Um ponto importante na decisão de retornar estaria ligado ao tempo de permanência no país de destino. Zakharenko ${ }^{23}$, trabalhando com dados American Current Population Survey (CPS), encontrou forte relação entre o tempo de moradia no país de destino e a decisão de retornar, sendo esta relação mais forte que a questão de gênero ou as variáveis educacionais: pessoas que moram há mais tempo no país de destino têm menor propensão a retornar.

Outro fator que pode contribuir na decisão sobre o retorno pode estar ligado às oportunidades de se transnacionalizar ${ }^{24}$, que é muito influenciado pela perspectiva da possibilidade de transformar o retorno não em um movimento definitivo, mas em um processo de circularidade.

Este aspecto está intimamente ligado a questões de política migratória que favorecem a integração dos imigrantes. O caso de Portugal é exemplar, pois permite aos imigrantes dos países de língua portuguesa, um processo de

\footnotetext{
${ }^{20}$ SAYAD, Abdlmalek. O Retono.

${ }^{21} \mathrm{GMELCH}$, George. Returning migration.

22 Ibidem.

23 ZAKHARENKO, Roman. Return Migration: an empirical investigation.

${ }^{24}$ SIQUEIRA, Sueli. Emigração internacional e o retorno a terra natal: realizações e frustrações.
} 
naturalização mais rápido ${ }^{25}$, o que pode contribuir para facilitar o retorno, principalmente de brasileiros. Com a garantia de poder voltar a Portugal, caso a nova estadia no Brasil não leve ao resultado esperado, estes imigrantes, detentores da dupla nacionalidade ou mesmo da residência permanente, estariam mais propensos a buscar entre os dois países aquele que oferece as melhores oportunidades. Assim estaríamos frente a uma situação de circularidade latente que pode ou não se manifestar, pois depende de vários fatores. Este caso é diverso da idéia de uma circularidade clássica onde o migrante pertence a dois mundos e transita entre $\mathrm{eles}^{26}$.

\section{A metodologia}

Os resultados aqui apresentados têm origem em pesquisa realizada sobre a migração de retorno de brasileiros em Portugal, financiada pelo CNPq. Este levantamento ("survey") foi realizado junto a 663 brasileiros retornados de Portugal e constou da aplicação de um questionário em municípios da região Leste do Estado de Minas Gerais e de Rondônia. O instrumento de coleta era composto de 33 perguntas, versando sobre vários aspectos do processo migratório e das razões para o retorno.

O levantamento de campo teve por base a metodologia "bola de neve", suas adaptações ${ }^{27}$ e a sua utilização no caso de imigrantes brasileiros ${ }^{28}$. Nesta técnica, escolhe-se inicialmente um grupo aleatório de entrevistados que, ao final da entrevista, identificam outros elementos que pertençam à população-alvo de interesse. Esse processo pode ser executado em ondas sucessivas, obtendo-se referências ou informações a partir do próprio entrevistado. O ideal é solicitar a cada entrevistado a indicação de dois nomes, um de seu conhecimento próximo e outro mais afastado com o qual ele não tenha ligação. Esta técnica permite coletar informações em grupos distintos de indivíduos.

Para a escolha dos municípios onde os levantamentos seriam realizados, optou-se por utilizar os dados do universo do Censo 2010. Nesse Censo perguntou-se nos domicílios se alguma pessoa que ali tenha residido estaria morando no exterior. Estas informações permitiram a construção do mapa a seguir, onde são indicados os municípios com maior proporção de emigrantes para Portugal, em relação à população total da cidade.

\footnotetext{
${ }^{25}$ Cf. <http://www.oi.acidi.gov.pt/docs/Estudos_Ol/Estudo45_WEB.pdf>.

${ }^{26}$ ASSIS, op. cit.

${ }^{27}$ SALGANIK, Matthew. J.; HEKATHORN, Douglas D. Sampling and estimation in hidden populations using respondent-drive sampling.

${ }^{28}$ SALES, Teresa. Brasileiros longe de casa; MARTES, Ana Cristina Braga. O compromisso do retorno: remessas de emigrantes brasileiros (relatório final).
} 


\section{FIGURA 1}

\section{Proporção de emigrantes para portugal em relação à população total dos municípios. Brasil - 2010}

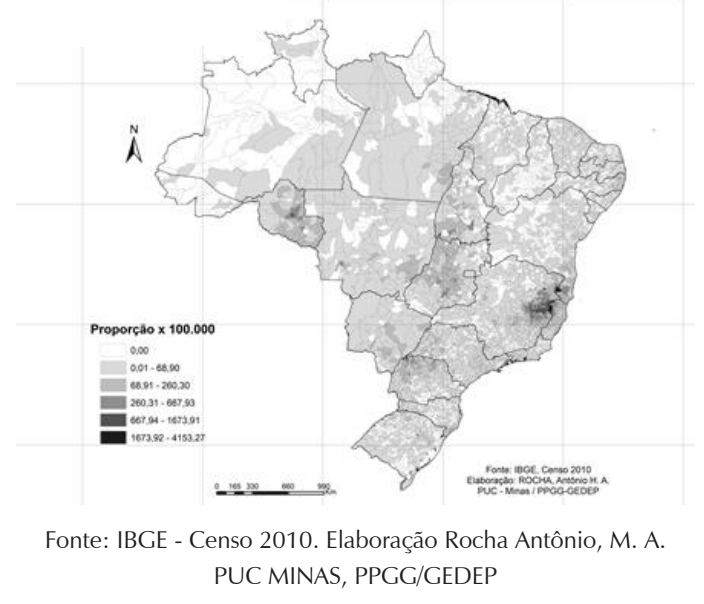

\section{O perfil do migrante retornado}

\subsection{A estrutura por sexo e idade}

No levantamento realizado, foram ouvidos 368 imigrantes retornados do sexo masculino (55,5\%) e 295 imigrantes do sexo feminino (44,5\%). Apesar de reconhecido o perfil feminino da migração para Portugal é importante considerar que há diversidade na situação dos retornados, uma vez que a empregabilidade das mulheres imigrantes em tempos de crise é maior que as dos homens, o que pode contribuir para uma diferenciação entre os retornados.

A idade média dos entrevistados no momento da entrevista ficou em 34,4 para os homens e 33,3 para as mulheres. Quando observado o momento da migração e do retorno, as idades médias foram de 26,6 para as mulheres e de 27,0 para os homens na primeira situação e de 30,8 para as mulheres e 31,6 para os homens no retorno.

A estrutura etária da população levantada, considerando estes dois momentos -, migração e retorno - é apresentada a seguir e se observa a concentração, mais de 50\% dos casos, para ambos os sexos, no grupo etário de 20 a 29 anos no momento da emigração. Importante destacar a presença de pessoas no grupo etário dos menores de 20 anos (17,1\% dos homens e 19,0\% das mulheres) que incorporam jovens de 18 e 19 anos, em sua maioria, e menores de idade que fizeram este deslocamento para a reunião familiar e os que viajaram em companhia dos pais. Neste particular é relevante considerar informações colhidas 
junto a representantes do Governo municipal de Governador Valadares ${ }^{29}$ que indicavam haver uma cultura migratória na região que "forçava" os jovens a fazer este trajeto quando completavam a maior idade. Prova deste "destino" era o reduzido número de estudantes nas classes de segundo grau, quando chegava a maior idade, o que acontecia para a maioria, na segunda série.

\section{Gráfico 2}

\section{Pirâmide etária dos entrevistados no momento da emigração}

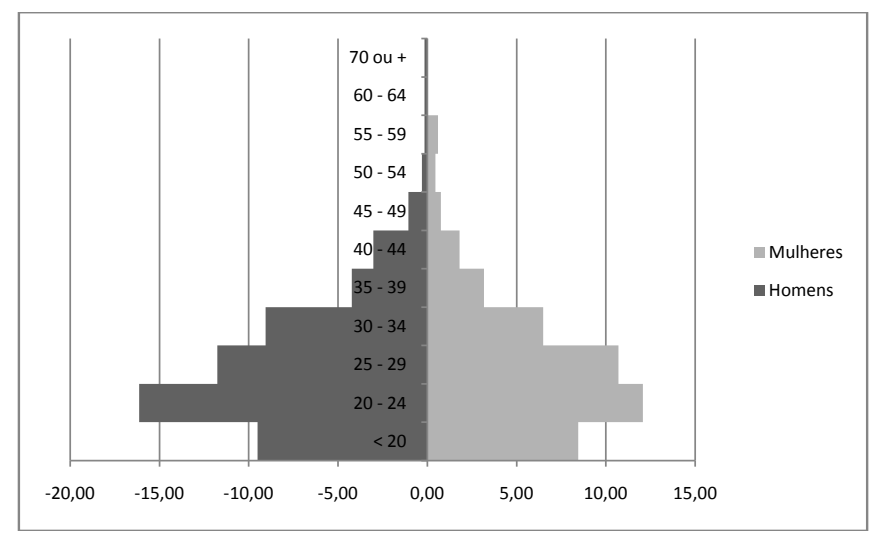

Fonte: pesquisa amostral

\section{Gráfico 3}

Pirâmide etária dos entrevistados no momento do retorno

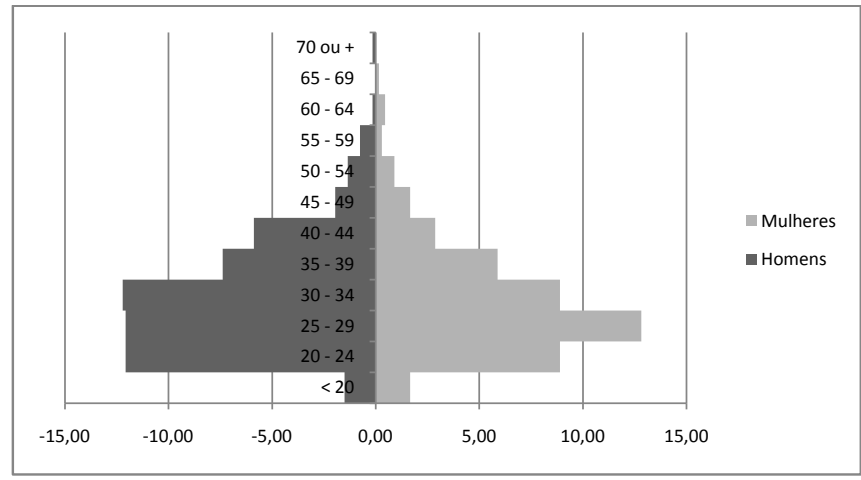

Fonte: pesquisa amostral

\subsection{Estado Civil e Instrução}

Considerando os dois momentos abordados no levantamento - a entrevista e a emigração, observa-se, na tabela a seguir, que 51,4\% dos

\footnotetext{
${ }^{29}$ Entrevista com o Senhor Secretário de Assistência Social de Governador Valadares
} 
entrevistados eram solteiros quando da emigração, sendo que 44,7\% das mulheres e 56,8\% dos homens estavam nesta situação. Nas outras categorias, não há uma diferença grande entre homens e mulheres no momento da emigração, salvo quando observado os separados e divorciados em que o número de mulheres supera o de homens.

No momento da entrevista, a maioria dos entrevistados, tanto do sexo masculino $(48,1 \%)$ como feminino $(44,4 \%)$ se declarou casada. Os solteiros representam $32,0 \%$ do total (37,5\% dos homens e $25,1 \%$ das mulheres).

Em relação ao nível de instrução, observa-se que a maioria dos entrevistados $(37,9 \%)$ declarou ter, como nível de instrução mais elevado, o 1 o grau completo, seguido por aqueles que declararam não ter completado o 1 o grau $(27,9 \%)$. Somente $12,1 \%$ dos entrevistados tinham o segundo grau completo e 5,8\% chegaram a se graduar ou frequentavam um curso superior. Estes dados mostram alguma discrepância em relação às pesquisas realizadas com brasileiros na Europa e em Portugal ${ }^{30}$ que mostram uma predominância de pessoas com o segundo grau completo na comunidade de brasileiros. Esta diferença estaria, possivelmente, ligada ao tipo de levantamento realizado neste trabalho que privilegiou as pequenas cidades, nas quais o impacto da migração internacional é mais importante.

Tabela 1 - Estado Civil dos migrantes retornados antes da migração e no momento da entrevista

\begin{tabular}{|c|c|c|c|c|c|c|c|c|c|c|c|c|}
\hline \multicolumn{9}{|c|}{ Antes da Migração } & \multicolumn{7}{c|}{ Depois da Migração } \\
\hline Estado Civil & Homem & Mulher & & Total & & Homem & & Mulher & & Total & \\
\hline & VA & $\%$ & VA & $\%$ & VA & $\%$ & VA & $\%$ & VA & $\%$ & VA & $\%$ \\
\hline Solteiro & 138 & 37,5 & 74 & 25,9 & 212 & 31,9 & 209 & 56,8 & 132 & 44,7 & 341 & 51,4 \\
\hline Casado & 177 & 48,1 & 131 & 44,4 & 308 & 46,4 & 134 & 36,4 & 107 & 36,2 & 241 & 36,3 \\
\hline $\begin{array}{c}\text { Separado/ } \\
\text { Divorciado }\end{array}$ & 21 & 5,7 & 35 & 11,8 & 56 & 8,4 & 10 & 2,7 & 26 & 8,8 & 36 & 5,4 \\
\hline Viúvo & 1 & 0,27 & 10 & 3,38 & 11 & 1,7 & 1 & 0,27 & 8 & 2,7 & 9 & 1,3 \\
\hline Vivendo junto & 31 & 8,4 & 45 & 15,3 & 76 & 11,4 & 14 & 7,4 & 22 & 7,4 & 36 & 5,4 \\
\hline & 368 & 100 & 295 & 100 & 663 & 100 & 368 & 100 & 295 & 100 & 663 & 100 \\
\hline
\end{tabular}

Fonte: Pesquisa Amostral

\subsection{Trabalho}

Ao perguntar sobre a ocupação, 53,5\% dos entrevistados declararam trabalhar no setor de serviços e comércio e 34,7\% na construção civil. Quando observados separadamente homens e mulheres, no caso dos primeiros, 61,4\% estavam atuando na construção civil e $87,1 \%$ das mulheres no setor de serviços e comércio.

\footnotetext{
${ }^{30}$ MALHEIROS, Jorge (org.). A Imigração Brasileira em Portugal; GOIS, Pedro et alii. Segunda ou terceira vaga? As características da imigração brasileira recente em Portugal.
} 
Por conta da diversidade de ocupações e atividades exercidas há dificuldade em se definir a remuneração média dos imigrantes. No entanto, no levantamento, observou-se que o valor mensal recebido pelo trabalho ficava, para a maioria, entre $\mathrm{R} \$ 2.500,00$ a $\mathrm{R} \$ 3.000,00$.

Importante lembrar que somente uma ínfima parte dos entrevistados $(5,9 \%)$ declarou ter saído do Brasil com visto de trabalho. Apesar de um grande número ter ficado por algum tempo em situação irregular em Portugal, 316 pessoas conseguiram regularizar a sua situação. Mesmo assim, $46,8 \%$ dos entrevistados declararam que trabalhavam sem uma permissão para tal, ou seja, na maioria dos casos sem contrato formal.

As jornadas de trabalho são longas e em 42,8\% dos casos chegam a 52 ou mais horas semanais. A rotatividade no trabalho é também fator importante, pois o número de pessoas que só teve um emprego durante a sua estadia em Portugal não chega a 7,0\% dos entrevistados, enquanto aqueles que tiveram 2 empregos correspondem a 23,6\%, 3 empregos 16,4\% e que declararam 4 ou mais empregos foram $53,1 \%$ do total.

Para a maioria dos entrevistados (54,4\%), o tempo médio para arrumar um emprego não ultrapassou uma semana após a chegada em Portugal, sendo que 12,4\% dos pesquisados já saiu do Brasil com o emprego previamente acertado, via a atuação da rede social. A situação de desemprego em Portugal foi experimentada por 41,0\% dos entrevistados.

Ao se analisar a ocupação por setor de atividade antes e após o retorno, observa-se que praticamente todos os retornados exerceram alguma atividade durante o período de residência em Portugal. No entanto, quando do retorno, 26,2\% dos entrevistados declararam não estar trabalhando no momento da pesquisa.

Dos que estavam atuando no setor da construção civil no momento da entrevista, 84,8\% trabalharam no mesmo setor quando viviam em Portugal. Para os que voltaram e se empregaram no setor de comércio e serviços, $64,2 \%$ atuaram neste mesmo setor no país de destino.

Importante notar que $47,1 \%$ dos que se dedicavam a atividades na área da agricultura quando da pesquisa, trabalharam no ramo da construção civil durante o período da migração. Tal situação pode indicar um projeto migratório voltado para o investimento na área agrícola, mesmo porque é uma atividade muito importante nas comunidades visitadas. Em especial, no estado de Rondônia onde os relatos dos entrevistados apontavam para a utilização do projeto migratório como uma forma de investimento na atividade agrícola. 
Tabela 2 - Imigrantes retornados por setor de atividade no Brasil, no momento da pesquisa, e em Portugal

\begin{tabular}{|c|c|c|c|c|c|c|c|c|c|c|c|c|}
\hline \multirow{3}{*}{\begin{tabular}{|l} 
Setor de \\
atividade no \\
Brasil no \\
momento da \\
pesquisa \\
\end{tabular}} & \multicolumn{12}{|c|}{ Setor de atividade em Portugal } \\
\hline & \multicolumn{2}{|c|}{ Agricultura } & \multicolumn{2}{|c|}{ Indústria } & \multicolumn{2}{|c|}{$\begin{array}{c}\text { Comércio e } \\
\text { Serviços }\end{array}$} & \multicolumn{2}{|c|}{$\begin{array}{c}\text { Construção } \\
\text { Civil }\end{array}$} & \multicolumn{2}{|c|}{ Sem Ocupação } & \multirow{2}{*}{\begin{tabular}{|l|} 
Total \\
V.abs \\
\end{tabular}} & \multirow[b]{2}{*}{$\%$} \\
\hline & V.abs & $\%$ & V.abs. & $\%$ & V.abs. & $\%$ & V.abs & $\%$ & V.abs. & $\%$ & & \\
\hline Agricultura & 14 & 27,5 & 1 & 2,0 & 12 & 23,5 & 24 & 47,1 & 0 & 0,0 & 51 & 7,7 \\
\hline Industria & 2 & 10,5 & 2 & 10,5 & 11 & 57,5 & 4 & 21,1 & 0 & 0,0 & 19 & 2,8 \\
\hline Comércio/Serv. & 17 & 5,0 & 8 & 2,3 & 217 & 64,2 & 92 & 27,2 & 4 & 1,2 & 338 & 51,2 \\
\hline Construção Civil & 4 & 5,1 & 0 & 0,0 & 8 & 10,1 & 67 & 84,8 & 0 & 0,0 & 79 & 11,9 \\
\hline Sem Ocupação & 18 & 10,5 & 6 & 3,5 & 106 & 61,0 & 42 & 24,4 & 0 & 0,0 & 173 & 26,2 \\
\hline Total & 55 & 8,3 & 17 & 2,5 & 354 & 53,6 & 229 & 34,8 & 4 & 0,6 & 660 & 100,0 \\
\hline
\end{tabular}

\subsection{Remessas}

Dos entrevistados, 86,1\% declararam enviar remessas para o Brasil. O valor médio mensal enviado ficava próximo a $\mathrm{R} \$ 1.175,05$. O meio mais utilizado para os envios eram as empresas de remessas usadas por 66,5\% dos entrevistados, que mandavam dinheiro para o país de origem, seguido por aqueles que utilizavam os bancos, $28,7 \%$ e o restante utilizava os serviços dos correios (3,8\%) ou amigos (1,0\%).

Quando perguntados sobre a finalidade dos envios, vários pontos foram levantados e as seguintes respostas se destacam: a ajuda a familiares apareceu em 55,2\% dos casos; o pagamento de contas foi indicado 37,4\% das vezes. Cabe lembrar que no conjunto destas contas, para alguns, estavam o ressarcimento dos empréstimos contraídos para se fazer a migração. A compra de imóvel foi citada em $25,6 \%$ dos casos e as remessas como aplicação financeira apareceu em $26,6 \%$ das vezes.

\subsection{Avaliação do processo migratório}

Avaliando o processo migratório, 74,2\% dos entrevistados indicam que a situação de vida em Portugal era melhor do que as condições de vida no Brasil antes da migração. 63,2\% dos imigrantes conseguiram acumular algum capital enquanto viviam no exterior. No entanto, quanto perguntados sobre a situação de vida hoje, no momento da entrevista, comparada com a experiência em Portugal, 67,7\% classificam que o momento atual no Brasil é melhor do que a situação vivida em Portugal. Destes, 40,8\% justificam a avaliação como positiva por estar perto da família e amigos. Ao serem perguntados sobre uma avaliação da migração, 88,1\% afirmaram que a decisão de emigrar gerou resultados positivos.

Em avaliação do processo migratório, 46,5\% acham que a migração resultou em sucesso, 5,1\% consideraram um fracasso e 48,3\% viram coisas 
boas e más, não tendo chegado a uma avaliação absoluta. No entanto, apesar da avaliação positiva, 67,9\% dos entrevistados desaconselhariam um amigo a tentar a sorte em Portugal. Destes, 53,1\% justificam sua opinião por conta da crise econômica.

Ainda dentro do processo de avaliação da estada em Portugal, quando consultados sobre o que mais desagradou no exterior, 41,0\% dos entrevistados citam o preconceito contra o imigrante. Ao relatar o que mais agradou, são apontadas as possibilidades de lazer (23,7\%), o baixo custo de vida $(13,1 \%)$ e a qualidade de vida $(10,1 \%)$.

\subsection{0 retorno}

Duas causas foram apontadas para o retorno dos imigrantes. A primeira e mais importante, na visão dos entrevistados, são as questões familiares (45,2\%) e, em segundo lugar, a crise econômica (16,6\%). Quando questionados diretamente se a crise teve alguma importância na decisão de retornar ao Brasil, 43,6\% afirmam que ela foi levada em consideração.

Em termos da opção de local para se viver no Brasil quando do retorno, 83,4\% escolheram voltar para a mesma cidade de partida. A decisão de retornar foi compartilhada com outra pessoa em 42,5\% dos casos e em quase sua totalidade, (95\%) com alguém da família.

Em 52,5\% dos casos, o retorno aconteceu como planejado e para aqueles que o retorno não aconteceu como o esperado, 21,0\% pensava voltar em uma situação econômica melhor, 20,1\% voltaram antes do planejado, $13,7 \%$ não queria voltar e 16,2\% só fizeram o retorno por razões familiares.

Ao serem perguntados sobre a adaptação no Brasil, 68,0\% dos entrevistados indicaram estar plenamente adaptados no seu retorno e 88,4\% consideram que valeu a pena ter voltado para o país de origem. Quando perguntados sobre projetos futuros de nova migração, somente $25,8 \%$ pensam em fazer novo trajeto, tendo como principal destino (67,8\%) Portugal.

\section{Considerações finais}

Segundo Sayad ${ }^{31}$, o retorno é parte integrante do processo migratório. O sonho de rever a terra que deixou é, em muitos casos, o alento para suportar situações difíceis que são justificadas pela possibilidade de completar o projeto migratório e atingir o objetivo traçado no momento da partida.

Entretanto, esta visão do local de origem e mesmo o projeto inicial, vão se transformando com o tempo e podem ter a sua conclusão adiada ou

${ }^{31}$ SAYAD, op. cit. 
mesmo abandonada. Várias são as razões apontadas, mas o mais importante é que o momento de crise sempre se abate com mais força sobre os imigrantes, via a redução de postos de trabalho, ampliação da xenofobia contra os imigrantes e mesmo a redução do acesso a serviços públicos, como aconteceu na Espanha, na área de saúde.

Neste momento, o sonho do retorno toma novo fôlego e impele a uma nova jornada que poderá ser mais dura do que a de partida. Para alguns, o tempo no país estrangeiro foi excessivo e não há mais uma identidade possível com o passado. Para outros, o retorno significa o fracasso do projeto migratório, pois com a crise, o pouco que tinha foi perdido.

Em relação àqueles que voltam de Portugal foi perceptível o impacto da crise e as histórias mostraram situações de grande vulnerabilidade. Uma frase colhida junto à autoridade municipal na cidade de Governador Valadares, mostra a dimensão desta situação: "[...] os que voltam dos Estados Unidos, voltam relativamente bem, mas os que voltam de Portugal, a gente tem de ir buscar, pois não têm dinheiro para nada, nem para voltar"32.

Tal afirmativa faz sentido quando se observa que são os brasileiros o maior contingente daqueles que solicitam, em Portugal, o auxílio da Organização Internacional para a Migração (OIM) para o retorno. Neste caso, para alguns, além da passagem de volta era oferecido um pequeno recurso para o início de alguma atividade produtiva ou pequeno negócio. A OIM, por meio de parcerias com instituições brasileiras, oferecia também assistência para auxiliar o imigrante na sua reinstalação no país e início de sua atividade.

O que a experiência mostrou é que tais iniciativas, apesar de sua importância do ponto de vista pessoal do migrante, não surtiam os efeitos esperados, muitas vezes, pelo pouco conhecimento que os retornados tinham da realidade que os esperava no Brasil $^{33}$.

No plano governamental, pode-se ressaltar que não existem estratégias coordenadas para ajudar o imigrante retornado por parte das autoridades. A maioria se vê perdida numa sociedade "desconhecida" e enfrenta dificuldades para encontrar um emprego que valorize sua experiência obtida no exterior. E assim, esses imigrantes retornados acabam por abrir pequenos negócios que nem sempre são bem sucedidos, empenhando parcela importante dos recursos a duras penas conseguidos. A princípio, práticas de consultoria buscando informações quanto ao empreendedorismo, envolvendo obtenção

\footnotetext{
32 Entrevista com o Secretário de Desenvolvimento do Município de Governador Valadares - 2011

${ }^{33}$ OIM. Fatores positivos e obstáculos para a reintegração sustentável no Brasil.
} 
de crédito para financiamento e estudos de mercado, seriam de grande valia e potencializariam a possibilidade de sucesso e readaptação.

Por último é importante ressaltar que, mesmo não sendo projeto para o futuro imediato, para alguns uma nova emigração constitui-se em possibilidade. Mais forte ainda para aqueles que conseguiram a autorização de residência em Portugal, o que permite o retorno em caso de uma não adaptação no Brasil ou se melhorar a situação econômica na Europa.

Tal situação nos indica que, em breve, não estaremos mais analisando só a imigração, a emigração ou o trânsito, mas também o retorno como estágio de um projeto migratório mais amplo que envolve circularidades latentes.

\section{Bibliografia}

ARANGO, Joaquín. La explicación teórica de las migraciones: luz y sombra. Migración y Desarollo, n. 12, octubre 2003, p. 4-22.

ASSIS, Gláucia de Oliveira. Estar aqui, estar lá, o retorno dos emigrantes valadarenses ou a construção de uma identidade transnacional? Travessia: revista do imigrante, maio-agosto, 1995.

CASTILLO, Manuel Angel. Migraciones en el hemisferio: consecuencias y relaciones con la política social. Santiago de Chile: Celade/Cepal, 2003.

CASTLES, Stephen; MILLER, Mark. The age of migration: international population movements in the modern world. London: Macmillan, 2009.

GMELCH, George. Returning migration. Annual Review of Anthropology, v. 9, 1980, p. 135-159.

GOIS, Pedro; MARQUES, José; PADILLA, Beatriz; PEIXOTO, João. Segunda ou terceira vaga? As características da imigração brasileira recente em Portugal. Migrações, OI/ACIDI, n. 5, 2009, p. 111-133.

GOZA, Franklin. A imigração brasileira na América do Norte. Revista Brasileira de Estudos da População, v. 9, n.1, 1992, p. 65-82.

LEE, Everet S. Uma teoria sobre a migração. In MOURA, Hélio A. de (coord.). Migrações internas: textos escolhidos. Fortaleza: BNB/ETENE, 1980, p. 211-244.

MALHEIROS, Jorge (org.). A Imigração Brasileira em Portugal. Lisboa: ACIDI. 2007.

MARQUES, A. M. Denise. Circularidade na fronteira do Paraguai e Brasil: o estudo de caso dos "brasilguaios", 2009. Tese (Doutorado em Demografia). UFMG, Centro de Desenvolvimento e Planejamento Regional, Belo Horizonte.

MARTES, Ana Cristina Braga. O compromisso do retorno: remessas de emigrantes brasileiros (relatório final). São Paulo: Fundação Getúlio Vargas, 2005 (mimeo).

MASSEY, Douglas; ARANGO, Joaquín; HUGO, Graeme; KOUAOUCl, Ali; PELLEGRINO, Adela; TAYLOR, Edward. Worlds in motion. Undesrstanding international migration at the end of the millennium. Oxford: Clareon, 1998.

MCGOVERN, Patrick. Immigration, labour markets and employment relations: problems 
and prospects. British Journal of industrial relations, v. 48, n. 2, 2007, p. 217-235.

MOURA, Hélio A. de (coord.). Migrações internas: textos escolhidos. Fortaleza: BNB/ ETENE, 1980.

OIM - Organização internacional para a Migração. Fatores positivos e obstáculos para a reintegração sustentável no Brasil. Relatório de Pesquisa. Lisboa 2013.

PELLEGRINO, Adela. La migración internacional en América Latina y el Caribe: tendencias y perfiles de los migrantes. Santiago do Chile: Celade/CEPAL, 2003.

PIORE, Michael J. Birds of Passage: migrant labor in industrial societies. Cambridge: Cambridge University Press, 1979.

RAVENSTEIN, Ernest George. As leis da migração. In MOURA, Hélio A. (coord.). Migrações internas: textos escolhidos. Fortaleza: Etene, 1980, p. 19-88.

REZENDE, Dimitri. Reflexões sobre os sistemas de migração internacional: proposta para uma análise estrutural dos mecanismos intermediários. 2005. Tese (Doutorado em Demografia). Universidade Federal de Minas Gerais, Centro de Desenvolvimento e Planejamento Regional, Belo Horizonte.

RIOSMENA, Fernando; MASSEY, Douglas S. Uma comparación de los determinantes de la migración de retorno de latinoamericanos em los Estados Unidos. Caxambu: I Congresso da Associação Latino Americana de População-ALAP, 2004.

ROSSI, Pedro Linhares. Remessas de Imigrantes brasileiros em Portugal. SOCIUS working papers. Lisboa: Universidade Técnica de Lisboa, 2004.

SALES, Teresa. Brasileiros longe de casa. São Paulo: Cortez, 1999.

SALGANIK, Matthew J.; HEKATHORN, Douglas D. Sampling and estimation in hidden populations using respondent-drive sampling. Sociological Methodology, v. 34, 2004, p. 193-239.

SAYAD, Abdlmalek. O Retono. Travessia: revista do imigrante, número especial, 2000.

SIQUEIRA, Sueli. Emigração internacional e o retorno a terra natal: realizações e frustrações. Anais do V Encontro Nacional sobre Migração, ABEP, Campinas, 2007.

SJAASTAD, Larry. Os custos e os retornos da migração. In MOURA, Hélio A. de (coord.). Migrações internas: textos escolhidos. Fortaleza: BNB/ETENE, 1980, p. 115-144.

SOARES, Weber. Da metáfora à sustância: redes sociais, redes migratórias e migração nacional e internacional em Valadares e Ipatinga. 2002. Tese (Doutorado em Demografia), Universidade Federal de Minas Gerais, Belo Horizonte).

TÉCHIO, Kachia. Imigrantes brasileiros não documentados: uma análise comparativa entre Lisboa e Madri. Socius Working Papers, n. 1, Lisboa: Universidade Técnica de Lisboa, 2006.

VICENTE-Trinida. La migración latinoamericana en España. Atas de La Reunión de Expertos Migración Internacional y Desarollo em América Latina y el Caribe. Ciudad de México: CEPAL, noviembre de 2005.

ZAKHARENKO, Roman. Return Migration: an empirical investigation. Munich Personal Repec Archive. MPRA papers n. 13755, 2009. Disponível em : < http:// 
mpra.ub.uni-muenchen.de/13755/1/Ch2tmp.pdf>. Acesso em 12.01.2013.

ZLOTNIK, Hania. Théories sur les migrations internationales. In CASELLI, Graziella; VALLIN, Jacques; WUNSCH, Guillaume (orgs.). Démographie: analyse et synthèse. Les determinants de la migration. Paris: Editions INED, 2003.

\section{Abstract \\ Migration and crisis: \\ the return of Brazilian immigrants from Portugal \\ In face of the crisis that began in 2008, return migration became, worldwide, the scenery of the migration routes of the second decennium of the 21st century. In the case of Brazil, this movement is especially important, since the economic situation of the country, at that time, was more favorable to countries central to the capitalist system, working as an attractive factor and contributing to hasten return plans that were becoming latent. This text, using data from return immigrants, interviewed in the states of Minas Gerais and Rondônia, paints a picture of the situation lived abroad and in Brazil when migrating back.}

Keywords: international migration, return, migration project.

Recebido para publicação em 01/09/2013.

Aceito para publicação em 19/11/2013. Received for publication in September, 01 ${ }^{\text {th }}, 2013$. Accepted for publication in November, 19 2013.

ISSN impresso: 1980-8585

ISSN eletrônico: 2237-9843 